\title{
OBSERVATIONS ON THE GROWTH OF BLOOD VESSELS INTO THE CORNEA. APPLICATION OF A NEW EXPERIMENTAL TECHNIQUE
}

BY

\author{
MAURICE LANGHAM
}

Ophthalmological Research Unit of the Medical Research Council, Institute of Ophthalmology, London.

Few subjects in opthalmology are more important from the clinical point of view than opacification and vascularization of the cornea; moreover, the problems included have a wide physiological and pathological interest. The unsatisfactory state of our present knowledge of the fundamental processes involved has been pointed out in the foregoing article by Ashton and Cook (1953), who also give a review of the literature. The present paper describes experimental investigations undertaken to elucidate these matters further.

A new method of inducing a swelling and subsequent growth of vessels into the cornea has presented a unique opportunity for studying the underlying causes of these pathological phenomena. It has been shown (Langham, 1951) that a neutralized solution of the organic compound alloxan, when brought into contact with the cornea of the rabbit, can be used to initiate either a completely reversible swelling of the cornea with little or no vascularization, or a swelling followed by a dense ingrowth of vessels around the whole periphery of the cornea.

This method has been applied to the present problem in three ways:

(1) The study of the swelling and hydration of the cornea in relation to the growth of new vessels;

(2) The study of changes in metabolism and respiration following application of alloxan and preceding the growth of new vessels;

(3) The study of changes in permeability.

\section{Methods}

Adult rabbits weighing between $1 \cdot 9$ and $2 \cdot 5 \mathrm{~kg}$. were chosen for the experimental work; where required, nembutal solutions and ethyl chloride were used for anaesthesia. Fresh alloxan monohydrate was dissolved in distilled water, neutralized, and made up to an isotonic concentration, and then, if necessary, diluted with a solution of isotonic saline. The thickness of the cornea was measured by the optical device described by Maurice and Giardini (1951a). Corneal thickness was determined before beginning the experiments, rabbits being rejected if a significant difference in readings was found between the two eyes.

For the administration of the alloxan solution the animals were anaesthetized with intravenous nembutal. No anaesthetic was applied to the cornea. A hypodermic needle was introduced via the sclera to avoid corneal damage, and a known volume of alloxan solution was then mixed with the aqueous humour by rapid movement of the plunger of the syringe twelve times. After withdrawal of the 
needle, the exterior of the cornea was well washed with warm isotonic saline. All subsequent readings of the corneal thickness and the extent of vascularization were made on the conscious animal.

Analyses.-Lactic acid was determined by the method of Barker and Summersen (1941). Tissue proteins were denatured in an 8 per cent. solution of trichloroacetic acid. For corneal analysis precautions were taken to minimize post-mortem glycolysis, the corneae being excised, weighed, and denatured within one minute of the initiation of excision from the unconscious animal. Estimations, which included a standard made on the day of the experiment, were carried out immediately on completion of the experiment; this was found to be necessary because of the instability of lactic acid in aqueous solution. A standard constant-volume type of Warburg manometric apparatus was used for the determination of oxygen uptake and rates of anaerobic and aerobic glycolysis. For the determination of oxygen uptake, the centre well was filled with $0.2 \mathrm{ml} .20$ per cent. solution of potassium hydroxide, and $0.5 \mathrm{ml}$. water was placed in the side arm to prevent hydration of tissue. No suspending medium was used (deRoetth, 1950; Langham, 1952). All determinations were carried out at $37^{\circ} \mathrm{C}$., using air as the gas phase. For the determination of the rate of aerobic glycolysis a Krebs bicarbonate medium containing $100 \mathrm{mg}$. per cent. glucose was used with gas mixtures of 5 per cent. $\mathrm{CO}_{2}$ and 95 per cent. $\mathrm{O}_{2}$.

\section{Swelling, Opacification, and Vascularization of the Cornea}

The discovery of Dunn, Sheehan, and McLetcher (1943) that alloxan administered intravenously to rabbits led to a destruction of cells in the islets of Langerhans and to a state of diabetes has led to much pathological and physiological research on its mode and mechanism of action. Two of the most striking observations concern the very rapid manner in which this organic compound induces pathological changes in the islet cells of the pancreas, and the very fast rate at which this substance is destroyed in the body. Thus, after an intravenous dose of alloxan, lesions in the beta cells of the islets are apparent within 5 min. (Banerjee, 1944; Hughes, Ware, and Young, 1944), and after this time alloxan is no longer demonstrable in the blood (Archibold, 1945; Brückmann, 1946; Karrer, Koller, and Sturzinger, 1945; Leech and Bailey, 1945). These two characteristics are important to the present study, for it follows that the corneal changes observed depend upon the immediate action of alloxan, and, further, it would seem that alloxan moves rapidly into the tissue cells.

In preliminary experiments, solutions of alloxan were brought into contact with the cornea by three methods:

(i) continuous drip on to the epithelial surface,

(ii) intra-lamellar injection,

(iii) direct mixing with the aqueous humour.

Swelling of the cornea resulted in all cases, but it soon became apparent that the anterior chamber was the most suitable site as it presents a simple means of bringing a given amount of alloxan into direct contact with the cornea. Unless otherwise stated, this route of administration was used in all subsequent experiments. The average volume of the anterior chamber of adult rabbits is $0.25 \mathrm{ml}$., and, by mixing this volume with $0.25 \mathrm{ml}$. of a solution of alloxan, a known amount and concentration of alloxan may readily be introduced. The rate of flow of aqueous 
humour in the normal rabbit is of the order of 1 per cent. per minute, which means that the concentration of a substance in the anterior chamber will drop by at least 50 per cent. in less than one hour. This fact, together with the knowledge that alloxan injected intravenously is known to be destroyed within a few minutes, indicates that the percentage of injected alloxan diffusing into the cornea is small;

In the first series of experiments, the effect of increasing concentrations of alloxan on the living cornea was observed; all solutions were neutralized and brought to an isotonic concentration by the addition of sodium chloride. Solutions of isotonic sodium chloride or very low concentrations of alloxan gave no significant degree of corneal swelling. In the range of 0.01 to $0.05 \mathrm{M}$ (175 to $775 \gamma$ ), however,

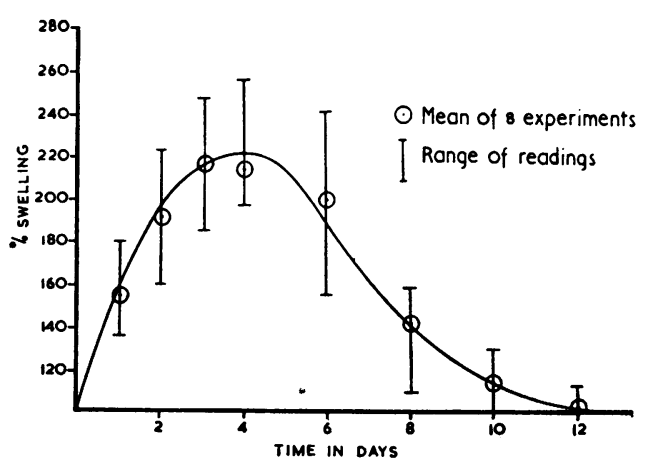

Fig. 1.-Increase in thickness of cornea after administration of $0.05 \mathrm{M}$ solution of alloxan into anterior chamber. an appreciable swelling of the cornea was induced (Fig. 1). The swelling occurred over the whole area of the cornea and increased in degree during the first 3 to 4 days, but then gradually decreased with a subsequent return to the initial thickness. The range of corneal swelling varied appreciably between groups of experiments made on different days, although care was taken to use freshly prepared solutions of alloxan; no reason could be found for this variation. No generalized vascularization of the cornea was observed in these experiments, although in certain cases there was a small ingrowth of vessels. appearing at the 5th to the 7th day. With the return of the main mass of the cornea to normal thickness, the blood in these newly-formed vessels slowly disappeared leaving an apparently normal cornea. A decrease in transparency was observed with the initiation of the swelling of the cornea, but full recovery was attained when the swelling had decreased to $10-15$ per cent. above normal.

When the concentration of alloxan was raised to $0 \cdot 15 \mathrm{M}$, a swelling of the cornea followed by a profuse vascularization was observed. The rate of increase of thickness of the central area of the

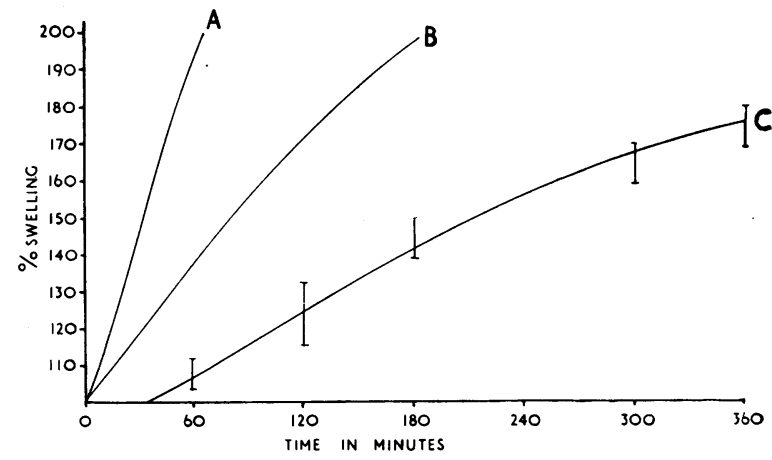

Fig. 2.-Effect of alloxan on swelling of cornea. Curve $\mathrm{C}=$ minimal vascularizing lesion.

Curve B (swelling of cornea after removal of epithelium) and Curve $A$ (swelling of cornea after removal of epithelium and endothelium) are included for comparison (Maurice and Giardini, 1951b.).

cornea after the injection of alloxan is recorded in Fig. 2. The swelling of the cornea continued until it was approximately $2 \frac{1}{2}$ to 3 times normal ( $24-48 \mathrm{hrs}$ after the initiation of the experiment); with the subsequent invasion of the cornea by new vessels, no significant reduction in corneal swelling was noted, although much later, between the 6th and 13th week, the thickness very slowly returned to nearly normal. 
The changes occurring in the blood vessels at the limbus are illustrated in Fig. 3. By microscopical examination, the small capillaries forming the limbal arcade are seen to have small, apparently dead-end, branches passing into the normal clear corneal substance. With a swelling of the cornea, these endbranches filled with flowing blood forming a cobblestoneshaped reticulum of interconnecting vessels. A marked engorgement of the episcleral and conjunctival vessels was seen on the 4th day and at this stage the small vessels showed signs of breaking up, leaving many small haemorrhages. During the next 24-48 hrs the growth of new vessels began, rapidly pushing inwards from the whole periphery towards the centre of the cornea. By the 8th day the engorgement of the perilimbal vessels had decreased, and the eye appeared much whiter; the zone of haemorrnage had also disappeared, the advancing front of new vessels being characterized by numerous small discrete spicules. Sometimes these spicules appeared isolated

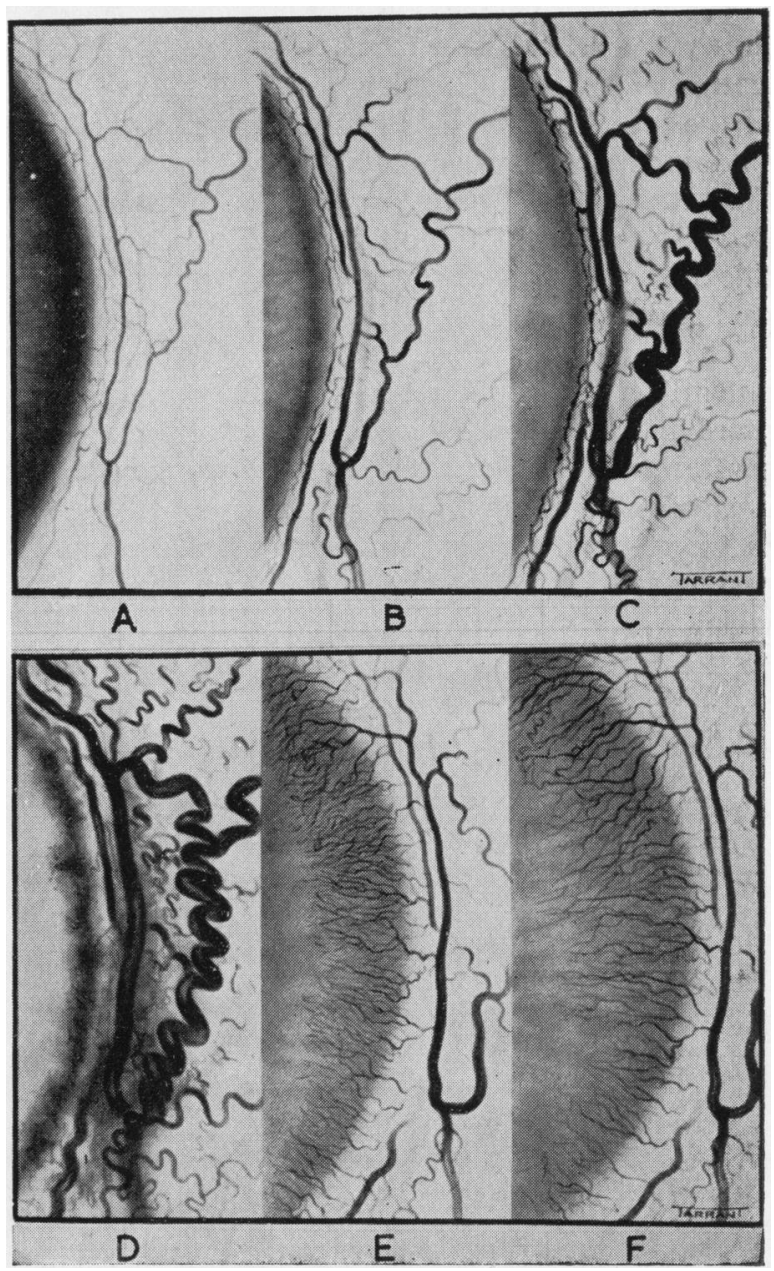

FIG. 3.-Changes in area of the corneo-scleral junction after inducement of a minimal vascularizing lesion. All drawings taken direct from the living animal.

A-F normal cornea and changes $2448,96,168$, and 240 hrs after administration of alloxan.

from the main vessels, but careful examination with the slit-lamp revealed that they were interconnected by avascular channels, which in due course filled with blood; no diffuse haemorrhage could be identified at this stage. By the 10th to 12th day, the number of small vessels near the limbus had decreased, being replaced by larger trunk-like vessels. A connection of vessels between layers of the cornea leading to a continuous flow of blood through the resulting circuits could now be distinguished. Vessel growth ceased by the 25th to 30th day, the cornea having become completely vascularized. During the following weeks, the corneal nerves appeared to increase in size and became readily apparent by retro-illumination. By the 8th week, the corneal thickness had begun to decrease, and by approximately the I6th week the cornea was only a little thicker than normal. The observation that the return of the cornea to normal thickness does not directly lead to an extrusion of blood from the vessels was made repeatedly, both in this and in the previous series of experiments. 
These experiments describe the effect of a varying concentration of alloxan on the cornea, and indicate the changes that may precede, and occur during, a vascularization of the mammalian cornea. Of interest are the findings, first, that the cornea $\equiv$ of the rabbit may swell rapidly to more than twice the normal thickness, and in so doing become very opaque and yet recover rapidly to its initial thickness before the extrusion of blood from vessels in the cornea; and second, that vessels will begin to grow into a swollen cornea which is just beginning to recover its normal thickness, and that cessation of this growth occurs with the thickness of the cornea. well above normal.

The finding that the growth of vessels into a swollen cornea may be halted in $\vec{\circ}$ an early phase of the recovery of the cornea to its normal condition prompted a $\overrightarrow{\vec{\omega}}$ more detailed investigation of what happens when the vessels tend to meet in the centre of the cornea. Clinically, a vascularization extending across the central $\frac{0}{0}$ area of the cornea is not infrequently observed. Similar observations were made $\dot{w}_{v}$ in the case of the alloxan lesion when the rate of growth of vessels around the perimeter of the cornea varied; in contrast, a series of experiments was made in which particular care was taken to induce an even vascularization. The needle

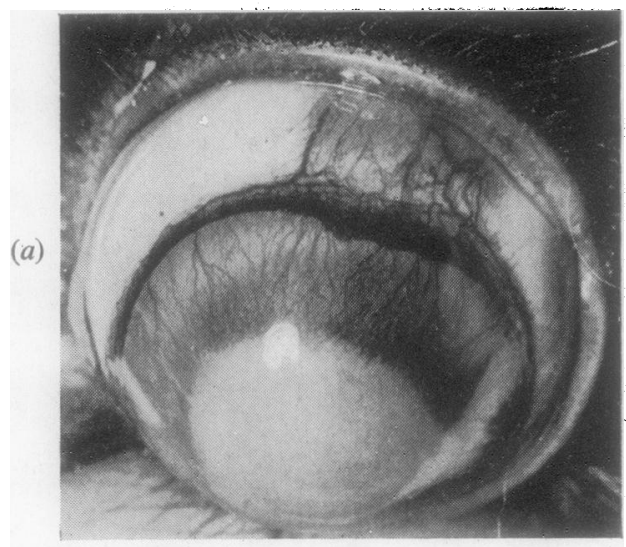
injected through scleral tissue was brought right behind the centre of the cornea and $\rightarrow$ the alloxan solution mixed carefully with the aqueous humour. With the induce- $\vec{\bullet}$ ment of vascularization, the rabbits were examined to see if the rate of growth of vessels was uniform around the whole periphery and if this was not so they were rejected (Fig. 4a-c). At approximately the 25 th to 30 th day, the growth of vessels had

FIG. 4.-Inducement of an even overall invasion of the cornea by new blood vessels. (a) 13th, (b) 19th, and (c) 22nd day after administration of alloxan.
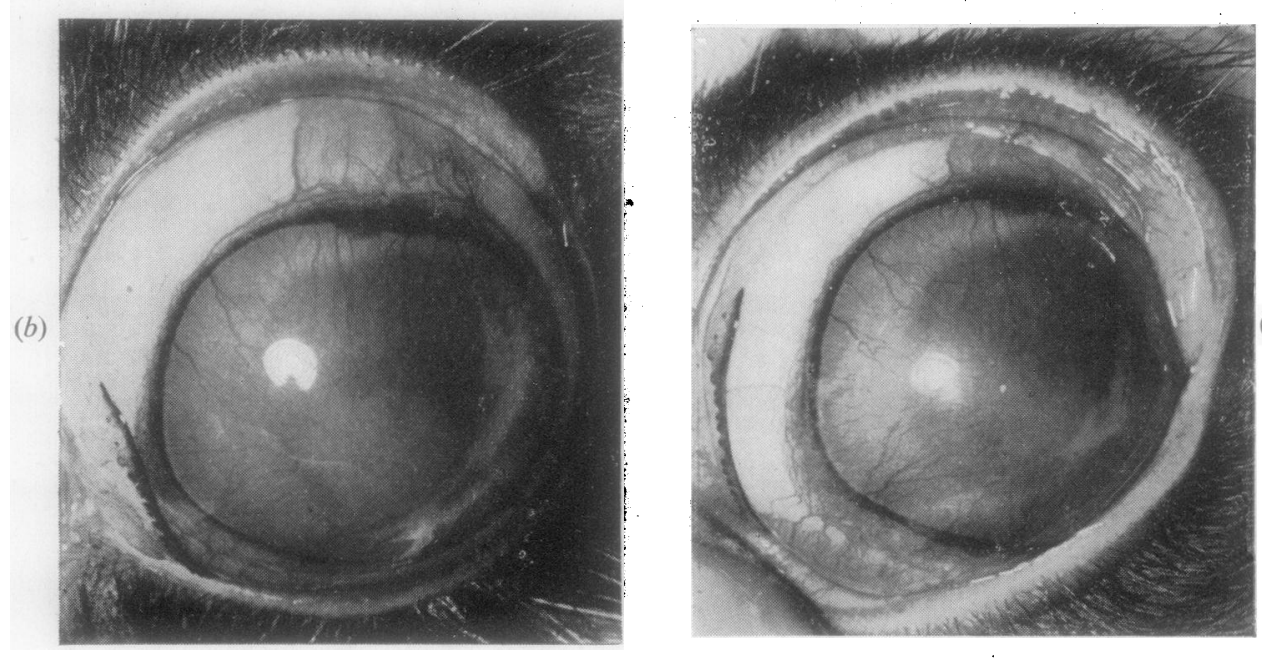
ceased, leaving a central area of cornea of approximately $2 \mathrm{~mm}$. radius completely devoid of vessels. Structurally, this central area was, like the vascularized area, grossly altered, its thickness being approximately $2 \frac{1}{2}$ times normal. Thus a marked thickening of the central area of the cornea can occur without becoming vascularized.

In a final series of experiments, the effects already described (i.e., a reversible swelling of the cornea returning to normal thickness within approximately 10 days, and a vascularizing lesion), were combined in the same eye by an injection of alloxan made directly into the cornea. $0.5 \mathrm{ml}$. neutralized isotonic solution of alloxan of varying concentration was injected into the corneal stroma on the temporal side, and a bleb produced extending to the limbal area. Swelling of the cornea occurred with all dilutions of alloxan, but below a concentration of $0 \cdot 15 \mathrm{M}$ no vascularization ensued. With a solution of $0 \cdot 31 \mathrm{M}$, vascularization from points around the whole periphery occurred, even though by the 10th to 15 th day the nasal half of the cornea was decreasing in thickness. By the 20th day, the nasal halt of the cornea had quite returned to normal thickness, yet the growth of blood vessels towards the centre of the lesion continued on the temporal side. In the following weeks the flow of blood through the vessels in the nasal half of the cornea gradually diminished, and, as suggested by their increasingly anaemic appearance, the vessels became smaller until by approximately the 10 th to 13 th week no more blood could be seen in the vessels. The pattern of vessel growth produced by the lesion is illustrated in Fig. $5 a$ and $b$. It was observed that the growth of vessels was directed towards the site of the lesion, branches from the

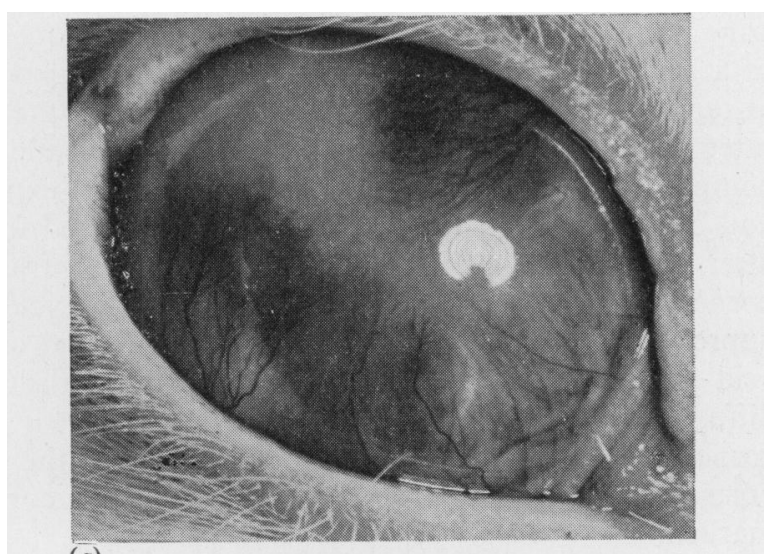

(a)

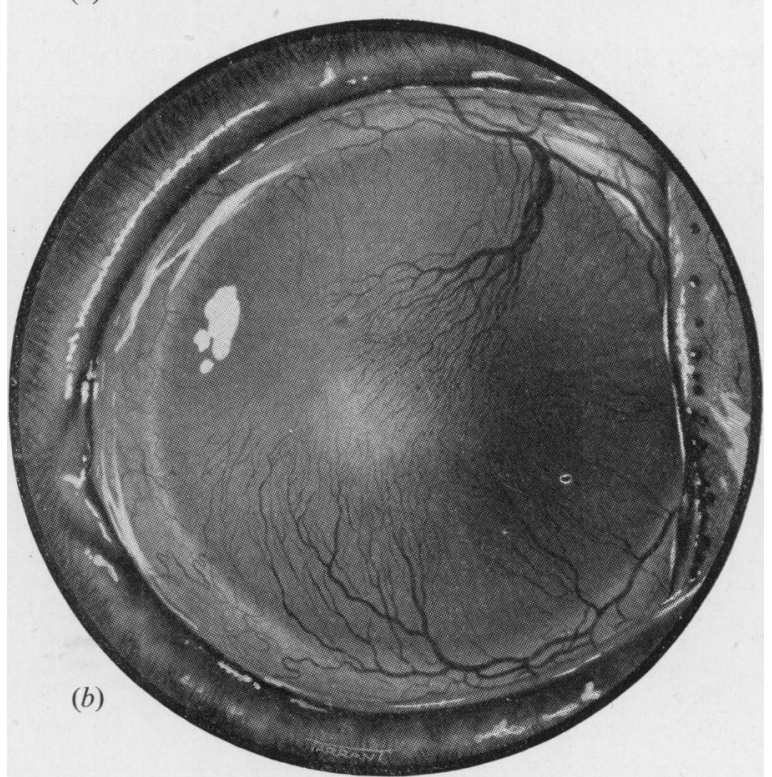

FIG. 5.-(a) Photograph and (b) painting of corneal vascularization illustrating directional properties of growth. Note that nasal side of cornea has returned to normal thickness and transparency, yet growth of blood vessels through the area continues. 
main vascular trunks being more numerous on the side nearest the lesion. The cornea around the site of the lesion and extending to the limbus remained markedly swollen (greater than $2 \frac{1}{2}$ times normal thickness), and yet the vascularization in this area remained sparse.

\section{Effect of Alloxan on Corneal Glycolysis and Respiration}

In normal rabbits it has been demonstrated that the concentration of lactic acid in the two corneae of the same animal is equal (Langham, 1952). The effect of alloxan on the concentration of lactic acid in the cornea of the living rabbit is recorded in Table I. The minimal dose of alloxan required to induce a vascularizing lesion of the cornea was injected into the aqueous humour of one eye of each of a group of eighteen rabbits. Four of these experimental animals were chosen at random and kept as controls; the corneae of the rest were excised after various intervals of time, weighed, and analysed for lactic acid. It will be seen from a comparison of the weights of the normal and experimental corneae (columns 1 and 2 of Table I) that corneal swelling increased from a time less than one hour after administration of the compound. In contrast with the steady increase in corneal swelling, the concentration of lactic acid in the experimental cornea approached normal after $24-48 \mathrm{hrs}$. The initial drop in concentration of lactic acid could be due either to an inhibition of corneal glycolysis or to an increased diffusion of lactic acid from the cornea. That it is caused by an inhibition of corneal glycolysis is suggested by the return of the concentration of lactic acid tc normal by the 24th to 28 th hour, at which time corneal swelling has become very marked.

\section{TABLE I}

EFFECT OF ALLOXAN ON CONCENTRATION OF LACTIC ACID IN LIVING CORNEAE

$2.5 \mathrm{mg}$. alloxan dissolved in a neutralized isotonic solution was injected into the anterior chamber of the experimental eye, and after a given time both corneae were removed for analysis.

\begin{tabular}{|c|c|c|c|c|c|}
\hline \multicolumn{2}{|c|}{$\begin{array}{c}\text { Corneae } \\
\text { (mg. wet weight) }\end{array}$} & \multirow{2}{*}{$\begin{array}{l}\text { Time } \\
\text { (hrs) }\end{array}$} & \multicolumn{2}{|c|}{$\begin{array}{l}\text { Lactic Acid Concentration } \\
\text { (mg. per cent. wet weight) }\end{array}$} & \multirow{2}{*}{$\stackrel{\text { Ratio }}{\text { Experimental/Control }}$} \\
\hline Control & Experimental & & Control & Experimental & \\
\hline $\begin{array}{r}86 \\
91 \cdot 4 \\
79 \cdot 7 \\
112 \cdot 7 \\
93 \cdot 3 \\
71 \cdot 6 \\
66 \cdot 2 \\
101 \cdot 3 \\
77 \cdot 3 \\
93 \cdot 1 \\
79 \cdot 4 \\
83 \cdot 6 \\
80.0 \\
78\end{array}$ & $\begin{array}{r}94.5 \\
102.8 \\
106.6 \\
121.1 \\
179.6 \\
144.3 \\
132.7 \\
171.5 \\
152.6 \\
139.4 \\
200.1 \\
199.1 \\
217.2 \\
289.5\end{array}$ & $\begin{array}{r}1 \\
1 \\
2 \\
2 \\
24 \\
24 \\
24 \\
24 \\
24 \\
48 \\
180 \\
180 \\
196 \\
196\end{array}$ & $\begin{array}{r}80 \cdot 3 \\
83 \cdot 1 \\
73 \cdot 3 \\
98 \cdot 7 \\
70 \cdot 3 \\
74.4 \\
78 \cdot 6 \\
69 \cdot 5 \\
71 \cdot 2 \\
42.4 \\
83.5 \\
102.7 \\
84.6 \\
86.5\end{array}$ & $\begin{array}{l}48 \cdot 7 \\
32 \cdot 2 \\
52 \cdot 7 \\
56 \cdot 9 \\
52 \cdot 6 \\
77 \cdot 0 \\
74 \cdot 8 \\
70 \cdot 1 \\
54 \cdot 7 \\
70 \cdot 0 \\
48 \cdot 2 \\
70 \cdot 8 \\
63 \cdot 7 \\
50 \cdot 5\end{array}$ & $\begin{array}{l}0.605 \\
0.385 \\
0.716 \\
0.575 \\
0.745 \\
1.05 \\
0.955 \\
1.01 \\
0.77 \\
1.65 \\
0.578 \\
0.690 \\
0.754 \\
0.585\end{array}$ \\
\hline
\end{tabular}

In order to obtain more definite information on this point, it was decided to test the effect of alloxan on the accumulation of lactic acid in the excised cornea. Normal corneae were removed from unconscious rabbits, and one was added to $2.5 \mathrm{ml}$. of a Kreb's Ringer phosphate solution containing glucose to a concentration of $100 \mathrm{mg}$. per cent. while the second was placed in $2.5 \mathrm{ml}$. of a similar solution to which had been added $0.1 \mathrm{ml}$. of a neutralized solution of freshly prepared alloxan to give a concentration of $100 \mathrm{mg}$. per cent. 
alloxan in the total solution. The flasks containing the corneae were then shaken for a period of one hour in a water bath at $37^{\circ} \mathrm{C}$. using air as the gas phase, after which time the solution plus corneae were analysed for lactic acid. In this experiment alloxan was found to cause a marked reduction in the concentration of lactic acid in the cornea, the ratio of concentration of lactic acid in the experimental corneae to that in the control corneae being $0.605^{ \pm 0} 0.02$ after $60 \mathrm{~min}$. incubation (4). This ratio includes the amount of lactic acid originally in the corneae, and in consequence inhibition of the production of lactic acid will be greater than the ratio suggests. Thus, the rate of corneal glycolysis in the living rabbit is reduced after the injection of alloxan into the anterior chamber.

Assuming that there is an initial reduction in corneal glycolysis, further scrutiny of Table I clearly indicates that its effect is temporary, for the concentration of lactic acid in the experimental cornea rises to a similar value to that found in the control cornea in spite of the marked corneal swelling. To test whether the rate of glycolysis does in fact return to normal, a manometric determination was made of the maximal rate of aerobic glycolysis on the excised tissue between the 24 th and 48th hour after administration of alloxan. The values based on the dry weight of the cornea, indicate that the rates of glycolysis in the two corneae do not differ significantly (Table II). It follows that alloxan does cause an initial inhibition of glycolysis, which is reversed with the disappearance of alloxan from the cornea. Table I shows that, with inducement of new vessel growth into the cornea, the concentration of lactic acid dropped again, an effect which may well be due to a more easy and rapid loss into the blood circulation.

TABLE II

AEROBIC GLYCOLYSIS OF CORNEAE EXCISED AFTER ADMINISTRATION OF ALLOXAN

\begin{tabular}{|c|c|c|c|c|c|}
\hline \multicolumn{2}{|c|}{$\begin{array}{c}\text { Corneae } \\
\text { (mg. wet weight) }\end{array}$} & \multirow{2}{*}{$\begin{array}{l}\text { Time } \\
\text { (hrs) }\end{array}$} & \multicolumn{2}{|c|}{$\begin{array}{l}\mu \mathrm{l} \mathrm{CO} \mathrm{C}_{22} \text { evolved per mg. } \\
\text { Dry Tissue per } \mathrm{hr}\end{array}$} & \multirow{2}{*}{$\begin{array}{c}\text { Ratio } \\
\text { Experimental/Control }\end{array}$} \\
\hline Control & Experimental & & Control & Experimental & \\
\hline $\begin{array}{l}74 \cdot 3 \\
92 \cdot 8 \\
87 \cdot 0 \\
80 \cdot 0 \\
78 \cdot 0 \\
85 \cdot 0\end{array}$ & $\begin{array}{l}202 \cdot 2 \\
173 \\
146 \cdot 5 \\
197 \cdot 5 \\
131 \\
231\end{array}$ & $\begin{array}{l}24 \\
24 \\
24 \\
48 \\
48 \\
48\end{array}$ & $\begin{array}{l}1.2 \\
1.6 \\
1.0 \\
1.47 \\
1.12 \\
1.31\end{array}$ & $\begin{array}{l}0.9 \\
1.5 \\
1 \cdot 1 \\
1.22 \\
1.28 \\
1 \cdot 1\end{array}$ & $\begin{array}{l}0.75 \\
0.935 \\
1.1 \\
0.83 \\
1.14 \\
0.84\end{array}$ \\
\hline
\end{tabular}

The effect of alloxan on the oxygen uptake of the living cornea was determined by removal of the corneae at various times after the administration of alloxan; the rates of oxygen uptake are recorded in Table III.

TABLE III

OXYGEN UPTAKE OF CORNEAE EXCISED AFTER ADMINISTRATION OF ALLOXAN

\begin{tabular}{|c|c|c|c|c|c|}
\hline \multicolumn{2}{|c|}{$\begin{array}{l}\text { Corneae } \\
\text { (mg. wet weight) }\end{array}$} & \multirow{2}{*}{$\begin{array}{l}\text { Time } \\
\text { (hrs) }\end{array}$} & \multicolumn{2}{|c|}{$\begin{array}{c}\text { ul Oxygen Uptake per mg. } \\
\text { Dry Tissue per hr }\end{array}$} & \multirow{2}{*}{ Ratio } \\
\hline Control & Experimental & & Control & Experimental & \\
\hline $\begin{array}{l}73.0 \\
73 \cdot 5 \\
83 \cdot 3 \\
91 \cdot 5 \\
61 \cdot 1 \\
80 \cdot 0\end{array}$ & $\begin{array}{l}183.9 \\
177.0 \\
133.6 \\
157.4 \\
130.8 \\
261.7\end{array}$ & $\begin{array}{r}24 \\
24 \\
24 \\
120 \\
120 \\
120\end{array}$ & $\begin{array}{l}0.84 \\
0.925 \\
0.60 \\
0.70 \\
0.91 \\
0.77\end{array}$ & $\begin{array}{l}0.65 \\
0.71 \\
0.44 \\
0.20 \\
0.50 \\
0.31\end{array}$ & $\begin{array}{l}0.77 \\
0.765 \\
0.73 \\
0.286 \\
0.55 \\
0.40\end{array}$ \\
\hline
\end{tabular}


It is clear that in these experimental conditions alloxan does lead to a marked and prolonged inhibition of the oxygen uptake of the cornea.

\section{Permeability of Corneal Tissue}

Gross changes in the permeability of the corneal tissue and of the capillary endothelium lining the limbal vessels of the cornea were studied, using the watersoluble vital dye Pontamine sky blue $(5 \times) ; 5 \mathrm{ml}$. of a 5 per cent. aqueous solution of this dye may be injected intravenously into the conscious rabbit without immediate injurious reaction; after 4 or 5 weeks, however, the animal usually dies. The dye was injected into normal rabbits and its diffusibility into the aqueous humour and cornea was studied by slit-lamp observation and aqueous humour puncture. No dye penetrated either across the blood-aqueous barrier, or into the cornea from the limbal arcades in the normal rabbit. In contrast, it was observed that the dye rapidly diffused across the walls of the conjunctival vessels and accumulated in the lymphatics of this tissue. To test the permeability of the normal corneal endothelial barrier to this dye, an isotonic solution was injected directly into the aqueous humour. After 12 hours the anterior chamber had become completely free of the dye, the lens was tinted, but the cornea, like the aqueous, was completely clear and uncoloured. Direct application to the surface of the cornea demonstrated that the normal epithelium is also impermeable to the dye. After administration of alloxan into the aqueous humour and the inducement of corneal swelling, an increase in permeability of the walls of the capillary limbal vessels occurred, as was indicated by a diffusion of the dye into the mass of the cornea.

Experiments to determine the increase in permeability of the endothelial and epithelial barrier were more difficult to assess, but it would seem that little if any dye passed across these barriers even in the swollen cornea. In confirmation of this conclusion, it was observed that fluorescein solution applied directly on the swollen cornea caused no staining as exhibited by a damaged epithelium. In these circumstances, it might be expected that the main transfer of fluid would occur from the limbal vessels. That this is so was indicated by biomicroscopical observation of an optical section of the cornea after the administration of alloxan. The angle between the slit-lamp beam and the microscope being set at $60^{\circ}$, and a magnification of 40 being used, the structural components of the cornea are readily distinguished. One hour after administration of alloxan no obvious changes could be seen in the epithelium or endothelium, but a slight increase in reflected light could be seen, in the area of the stroma lying just below the epithelium and by the second hour this was more enhanced as was indicated by numerous light and dark thin lines. With this increase in corneal swelling the corpuscles became ill-defined, especially in the area immediately below the epithelium. By the end of $24 \mathrm{hrs}$, corneal corpuscles could no longer be distinguished except near the endothelial surface, while in the area adjacent to the epithelium marked cleavage planes had become apparent. Even at this stage, however, no change could be observed in the epithelium and endothelium. It follows that, in this experimental condition, fluid transfer is mainly from the limbal region.

By contrast, in a similar experiment in which the endothelium in the central area of the cornea was damaged, the structural changes observed by the slit-lamp first began in the area adjacent to the endothelium, indicating that the fluid transfer in this case was predominantly from the aqueous. 


\section{Discussion}

The object of this experimental work has been to study some of the main metabolic and physical changes which may occur in a cornea whose normal function is disturbed, and to correlate these events with the phenomenon of the growth of new vessels into the cornea.

A considerable amount of research has already been devoted to the study of the water balance of the mammalian cornea (Cogan and Kinsey, 1942a, b; Kinsey and Cogan, 1942a, b; Pirie, Schmidt, and Waters, 1948; Davson, 1949; Maurice, 1951; Langham, 1952, 1953). It is generally agreed that the water content, or degree of hydration of this tissue, is maintained at a constant value by the special physical characteristics of the limiting membranes, comprising the stromal-epithelial and the stromal-endothelial barriers, the functional integrity of which depends on the active metabolism of the epithelial and endothial cells. Should the dehydrating mechanism of the cornea be unable to extract fluid fast enough to maintain its normal state, an increased hydration and swelling will result. Swelling takes place mainly in the stroma, a region which comprises by weight and thickness 90 per cent. of the whole cornea (Langham, 1952). The stroma is formed of an extracellular space of approximately $12-15$ per cent. and a cellular volume occupying the remaining 85-88 per cent. In consequence, stromal swelling can be due either to an increase in hydration of both the extracellular and the intracellular phases, or to the increase of one at the expense of the other. No attempt was made in the present study to determine the relative changes occurring in these two phases during the swelling of the cornea, but it would appear that the increase in hydration occurred initially and to a greater degree in the extracellular space. Thus, slit-lamp observation of an optical section of the cornea showed a separation of groups of stromal fibres, which was especially marked in the initial stages in the region below the epithelium.

The transparency of the cornea is intimately connected with its water content, which in the cornea of the living rabbit comprises 77 per cent. of its total weight. This value is the same in the cornea of both eyes and varies little in different rabbits (Duane 1949). Although the exact nature of the mechanism whereby hydration is maintained at this specific value is not yet known, it is of interest to observe its efficiency as exemplified in the present work. A cornea swollen to considerably above twice its normal dimensions and densely opaque recovered in a few days to assume a normal thickness and clarity. Certainly the factors governing the conditions essential for the maintenance of transparency are sufficiently effective to determine rapid recovery from a lesion of this nature. This efficiency in dealing with an abnormal content of fluid is even more striking when vascularization has occurred; in these circumstances the dehydrating mechanism has to cope with abnormally great fluid-traffic, but yet the cornea may resume its normal thickness while the circulation in these vessels is still maintained.

The normal mammalian cornea, bathed posteriorly by the aqueous 
humour and anteriorly by tear fluid, is devoid of vessels except in a narrow zone at its periphery. If the peripheral vessels grow into the cornea they must penetrate the extracellular phase, the permeability of which is determined mainly, if not wholly, by the state of the inter-fibrillar ground substance. This is a highly polymerized carbohydrate protein complex, which forms a viscous barrier to the diffusion of particles of relatively small molecular dimensions; thus it has been observed in the present study that the dye Pontamine sky blue does not ordinarily pass into the main mass of the stroma from the pericorneal capillaries. It would seem obvious that an invasion of the cornea by new vessels must be preceded by a decrease in the compactness of this extracellular volume. Thus it is significant that following the application of alloxan, an increased hydration of the cornea in the region of the limbal vessels is an essential pre-requisite to the ingrowth of vessels. This does not, however, preclude the possibility that in other circumstances vessels might grow into a cornea without this previous swelling; it is conceivable that a decrease in compactness might arise just as effectively from a loss of ground substance, even if the mechanism of corneal dehydration were functioning at a normal or even a super-normal level.

The difficulties of ascertaining the nature of the stimulus determining the growth of new vessels into the cornea may be gathered from the present work. After the administration of alloxan, changes in metabolism and structure precede vascularization. Specifically, the stimulus has been ascribed to asphyxia (Bessey and Wollbach, 1939; Johnson and Eckardt, 1940), to inflammation (Julianelle and Lamb, 1934), to toxins (Haessler, 1927), or to a fall in tissue tension (Cogan, 1948, 1949).

In this respect the recent work of Cogan deserves special consideration. He made small experimental lesions in the cornea of the rabbit and observed that a swelling in the region of the limbal vessels always preceded vascularization. On this and similar evidence he suggested that the vessels at the limbus are normally prevented from entering the cornea by the compactness of the tissue; should, however, this be sufficiently decreased, ingrowth of vessels would occur. He thus puts forward the view that the lowering of extravascular pressure in the cornea results in an engorgement of limbal vessels; saccular aneurysms form, which ultimately burst, and this is followed by the outgrowth of new capillaries. When the stroma becomes isotonic to the blood, and, in consequence, hypotonic to the tears and the aqueous humour, the cornea automatically returns to its normal state; in these circumstances water is withdrawn from the cornea which slowly becomes deturgesced, and, finally, blood is extruded from the corneal vessels.

In conclusion, it is of interest to consider a final point which indicates the complexity of this problem. It will be remembered that, in the reversible swelling of the cornea following the application of alloxan, after the vessels growing inwards from the periphery had reached a distance of 1 to $2 \mathrm{~mm}$., they ceased to grow even although the cornea was still more than twice its 
normal thickness and weight. Moreover, vascularization ceased in some instances when the pathological changes had passed their acute stage but the cornea was still swollen to twice its normal thickness. If this persistence of swelling is still confined to the extracellular phase at this stage, it would seem to follow that gross swelling of the cornea per se is not the sole stimulus for vascular growth. These are issues which require further study before any final conclusion can be made as to the nature of the stimulus to new vessel growth.

\section{Summary}

(1) A method is described for the inducement of a completely reversible swelling of the cornea with little or no vascularization, or of a swelling followed by a dense ingrowth of vessels around the whole periphery of the cornea. With the application of this technique, an investigation has been made of the phenomenon of the growth of new vessels into the cornea of the rabbit.

(2) The swelling and hydration of the cornea in relation to the growth of new vessels has been noted. Changes taking place in the thickness of the cornea before and during vascularization have been measured.

(3) It is shown that an increased hydration of the corneal area adjacent to the perilimbal capillaries is an essential pre-requisite to the invasion by blood vessels following the application of alloxan.

(4) Invasion of the cornea by blood vessels ceases when the swollen cornea enters a phase of recovery, even though the cornea is still greatly swollen.

(5) Extrusion of blood from vessels in the cornea does not precede the return of the cornea to a normal thickness and weight.

(6) When new vessels are growing evenly towards the centre of the cornea from the whole periphery, growth will cease leaving a small central area devoid of vessels, though grossly swollen.

(7) Changes in glycolysis and respiration which occur after the application of alloxan and before the growth of the new vessels have been measured. It has been shown that alloxan causes a marked inhibition of corneal glycolysis, but recovery ensues with disappearance of alloxan. The inhibition of respiration has been shown to be reversible.

(8) Changes in permeability preceding the growth of vessels into the cornea have been observed, using the vital dye, Pontamine sky blue. A considerable increase was noted in the permeability of the walls of the capillary vessels at the limbus of the cornea.

(9) The results are discussed in the light of present knowledge of the normal physiology of the mammalian cornea.

I should like to express my đeep gratitude to the director of research, Sir Stewart Duke-Elder, for his interest and unfailing advice and help during the course of this study, and to the Medical Research Council for defraying the cost of this research. I am also indebted to Miss S. Scotchbrook for her technical assistance. 


\section{REFERENCES}

ARChibold, R. M. (1945). J. biol. Chem., 158, 347.

AshtoN, N., and COOK, C. (1953). British Journal of Ophthalmology, 37, 193.

BANER and LANGHAM, M. (1951). Ibid., 35, 718.

BANERJEe, S. (1944). Lancet, 2, 658.

BARKer, S. B., and Summerson, W. H. (1941). J. biol. Chem., 138, 535.

BesSeY, O. A., and WolbaCH, S. B. (1939). J. exp. Med., 69, 1.

BrückmanN, G. (1946). J. biol. Chem., 165, 103.

Cogan, D. G. (1948). Trans. Amer. ophthal. Soc., 46, 457. (1949). Arch. Ophthal., Chicago, 41, 406.

and KINSEY, V. E. (1942a). Ibid., 27, 466. (1942b). Ibid., 28, 661 .

Davson, H. (1949). British Journal of Ophthalmology, 33, 175.

DEROETrH, A., Jr. (1950). Arch. Ophthal., Chicago, 44, 666.

DuANe, T. D. (1949). Ibid., 41, 736.

DunN, J. S., SheEhAN, H. L., and McLeTChI, N. G. B. (1943). Lancet, 1, 484.

HAESSLER, F. H. (1927). Trans. Amer. ophthal. Soc., 25, 412.

Hughes, H., WARE, L. L., and Young, F. G. (1944). Lancet, $1,148$.

Johnson, L. V., and ECKARDT, R. E. (1940). Arch. Ophthal., Chicago, 23, 899.

Julianelle, L. A., and LAMB, H. D. (1934). Amer. J. Ophthal., 17, 916.

KARRER, P., Koller, F., and StURZINGER, H. (1945). Helv. chim. Acta, 28, 1529.

KinSEY, V. E., and CoGAN, D. G. (1942a). Arch. Ophthal., Chicago, 28, 272.

L (1942b). Ibid, 28, 449.

LaNGHAM, M. (1951). Quoted in Ashton, Cook, and Langham (1951). (1952). J. Physiol., Lond., 117, 461. (1953). Ibid. In the press.

LeECH, R. S., and Bailey, C. C. (1945). J. biol. Chem. 157, 525.

MAURICE, D. M. (1951). J. Physiol., Lond., 112, 367. and GiardinI, A. A. (1951a). British Journal of Ophthalmology, 35, 169. (1951b). Ibid., 35, 791 .

Pirie, A., SChmidT, G., and WATERS, J. W. (1948). I Ibid., 32, 321. 